\title{
Study on 46 XY Disorders of Sex Development
}

Jesmin $\mathrm{E}^{1}$, Mohsin $\mathrm{F}^{2}$, Begum $\mathrm{NNF}^{3}$

DOI: https://doi.org/10.3329/jafmc.v14i2.45893

\begin{abstract}
Introduction: $46 \mathrm{XY}$ disorders of sexual development (DSD) include a wide sphere of phenotypes which can be ambiguous male genitalia with or without hypospadias, unambiguous female genitalia or dysgenetic gonads or any combination of them. Management of these patients depends on the aetiology, age at presentation, gender orientation and advancement in feminization.
\end{abstract}

Objectives: To assess the clinical, biochemical, radiological and chromosomal profile of the paediatric patients with suspected DSD attending a tertiary level healthcare centre and plan for appropriate management.

Materials and Methods: This cross-sectional study was carried out among 30 cases of $46 X Y$ DSD attending the paediatric endocrine unit of Bangladesh Institute of Research and Rehabilitation in Diabetes Endocrine and Metabolic Disorders (BIRDEM) General Hospital from May 2016 to April 2017. Clinical, biochemical, radiological and chromosomal evaluations were done to identify the cause of DSD.

Results: The mean age of the patients recruited in the study was 3.51 ( \pm 5.03 ) years ranging from 13 days old to 13 years old. Among these 30 patients, the chief complaint was ambiguous genitalia in $29(96.7 \%)$ cases, 1 (3.3\%) case with Micropenis and $1(3.3 \%)$ case with absence of development of secondary sexual characteristics. The gender of rearing was male in $23(76.7 \%)$ cases and rest as female. Among the patients 5 $(16.67 \%)$ patients were diagnosed with PAIS, 5 (16.67\%) patients with CAIS, $3(10 \%)$ patients had a deficiency of $5 \mathrm{aRD}$ and gonadal dysgenesis was found in $5(16.67 \%)$ patients. The corrective surgery was done in 5(16.67\%) patients, 16 (53.3\%) patients referred to surgeon for operative treatment and $7(23.3 \%)$ patients were prescribed to administer testosterone.

Conclusions: The early presentation, correct identification of the cause and initiation of cause-based treatment can abate the physical and psychosocial complications and may support better gender orientation related adjustability.

Key-words: $46 \mathrm{XY}$ disorders of sex development.

\section{Introduction}

Disorders of sex development (DSD) include a heterogeneous group of heritable disorders of sex determination and differentiation ${ }^{1}$ where there is a discrepancy in the chromosomal, gonadal, and anatomical sex ${ }^{2}$. DSD cases are detected mostly during the time of birth on the ground of atypical genital appearance; in other cases, the condition only becomes evident at the time of puberty ${ }^{3}$. Though, whether the diagnosis be early or late, there is persistent presence of one or more atypical deviation from normal sex determination (differentiation of the bipotential gonad into either testis or ovary) or differentiation (formation of the internal reproductive anatomy and external genitalia under hormonal influence) $)^{4}$ 46, XY DSD have lower virilization of genitals compared to normal $46, X Y$ individuals ${ }^{5}$. The 46 XY DSD is categorized into disorders of gonadal development and disorders of androgen synthesis and action. Disorders of gonadal development refer to gonadal dysgenesis whereas, disorders of androgen synthesis and action refer to 5 alpha-reductase deficiency (5aRD), androgen insensitivity, $17 \quad \beta$ hydroxy-steroid dehydrogenase deficiency etc².

The frequency of patients born with ambiguous genitalia estimated to be approximately 1 in 4,500-5,5006. Subjects presented with ovotesticular DSDs have been estimated ${ }^{7}$ to be in 1 in 100,000. Testicular or mixed gonadal dysgenesis is estimated ${ }^{8}$ to be approximately $1: 10,000$. Considering all genital anomalies including cryptorchidism and hypospadias, the rate ${ }^{9}$ may rise up to $1: 200$ to $1: 300$ among these, the incidence of 46, XY DSD has been estimated to be 1 in 20,000 births $^{10}$. The risk of gonadal tumours may be as high as $40 \%$ in individuals with dysgenetic gonads ${ }^{11}$. In fact, dysgenetic and undescended testes are listed as major risk factors for testicular cancer, which is the most common malignancy for men between the ages of 15 and 35 years $^{12}$.

The 46, XY disorders encompasses a wide spectrum of different conditions such as $46 \mathrm{XY}$ partial gonadal dysgenesis (Denys-Drash syndrome, Frasier syndrome), 46 XY complete gonadal dysgenesis (Swyer syndrome), ovotesticular DSD, testicular regression syndrome (vanishing testes syndrome), Leydig cell aplasia/hypoplasia, testosterone biosynthesis defects, POR gene abnormality, persistent Mullerian duct syndrome, 5 alpha-reductase type 2 deficiency syndrome, complete androgen insensitivity syndromes (CAIS) and partial androgen insensitivity syndromes (PAIS) ${ }^{13}$.

1. Lt Col Eva Jesmin, MBBS, DCH, FCPS, Classified Child Specialist of Paediatrics, Combined Military Hospital (CMH), Dhaka (E-mail: jesmin882@gmail.com) 2. Professor Fauzia Mohsin, MBBS, FCPS, Professor \& Head of Paediatrics Endocrinology Unit, Department of Paediatrics, BIRDEM General Hospital-II, Dhaka 3. Brig Gen Nurun Nahar Fatema Begum, SBP, MBBS, FCPS, FRCP, FACC, FSCAI, Independence Awardee, Professor \& Head of the Department of Paediatrics, AFMC, Dhaka. 
A careful clinical assessment of the neonate is essential as most DSD patients could be recognized at birth with the presence of ambiguous genitalia and earlier diagnosis allows for initiating a better treatment protocol ${ }^{14}$. Nevertheless, they may be diagnosed later in life in individuals with abnormal or delayed puberty or primary amenorrhea, cyclic hematuria in a male, inguinal hernia in a female, unanticipated virilization or gynaecomastia, infertility, or gonadal tumors ${ }^{12}$. The first steps for a correct diagnosis are taking family and prenatal history, thorough physical examination and evaluation of genital anatomy. These approaches are followed by a cytogenetic evaluation to assess chromosomal constitution and a combination of those may direct for the requirement for additional testing which may include endocrinological evaluation, imaging (most reliably ultrasonography $)^{15}$. Endoscopic and laparoscopic examination and gonadal biopsy are required in very few cases ${ }^{14}$.

The basic principles for the management of DSD include a multidisciplinary approach for gender assignment ${ }^{13}$. Initiation of appropriate treatment results in providential outcomes in terms of growth of sexual identity and adaptation ${ }^{16}$. As, several biologic factors such as genetic and hormonal influences contribute to gender identity, gender role behaviour, and sexual orientation in patients, also these conditions are modified by psychological, social, and cultural factors and altogether they guide the establishment of the social sex ${ }^{13}$. To establish female social sex in patients with 4XY DSD who have a uterus, hormonal therapy is introduced to stimulate the development of female sexual characteristics in patients with uterus. The treatment should stimulate normal puberty, mense and breast development. Age and response-based hormonal therapy are continued until the expected outcome is accomplished. Among the surgical interventions, feminizing Genitoplasty, Cliteroplasty, Vaginoplasty, Vulvoplasty, dilation of the blind vaginal pouch with acrylic molds ${ }^{17}$ or surgical neovagina to promote the development of a vagina adequate for sexual intercourse remained popular treatment choices when these patients wished to start sexual intercourse ${ }^{18}$. Contrarily, to establish male social sex for those patients with $4 X Y$ DSD who have been raised as males, testosterone replacement therapy is initiated between 10-11 years, simulating normal puberty. Common Surgical treatment in these cases includes Orthophaloplasty, Scrotumplasty with resection of the vaginal pouch, proximal and distal urethroplasty and orchidopexy as per requirement. Additionally, detection of undifferentiated gonadal tissue or testicular tissue suggests a high risk for germ cell tumours and Gonadectomy should be performed in such cases to risk out any malignant transformation ${ }^{14}$.

Psychological evaluation of primary caregivers is also crucially important to treat DSD patients. Sex assignment of children with ambiguous genitalia remains a difficult decision for the families involved ${ }^{19}$. Every couple that has a child with atypical genitalia must be assessed and receive counselling by an experienced psychologist, specialized in gender identity. A simple, detailed and comprehensive explanation about what to expect regarding integration in social life, sexual activity, need of hormonal and surgical treatment and the possibility or not of fertility according to the sex of rearing, should also be discussed with the parents, before the attainment of final social $\operatorname{sex}^{13}$. Healthy gender identity and the interaction of genetic constitution, physiology, and hormonal assignment and the sex of rearing shape an individual's psychological development ${ }^{20}$. Most of the well-treated DSD patients present a normal quality of life at adulthood.

\section{Materials and Methods}

This cross-sectional study was carried out among 30 cases of 46XY DSD attending the paediatric endocrine unit of Bangladesh Institute of Research and Rehabilitation in Diabetes Endocrine and Metabolic Disorders (BIRDEM) General Hospital from May 2016 to April 2017. Data including age at presentation, biochemical and radiological investigation, clinical diagnosis, treatment given were collected. Cases were diagnosed by clinical, hormonal and cytogenetic analysis. The clinical features examined for the diagnosis of DSD included genital ambiguity, apparent male genitalia with non-palpable testis, micropenis, hypospadias, apparent female genitalia with clitoromegaly, inguinal or labial mass. The hormonal assay was done to evaluate included luteinizing hormone (LH), folliclestimulating hormone (FSH), testosterone (T) and un-stimulated and/or stimulated 17-hydroxy progesterone 17(OH)P levels (where indicated). Abdominopelvic ultrasound was done for the localization of gonads (magnetic resonance imaging (MRI) also when required to determine the nature and structure of the internal sex organs and to detect any disagreement with external genital structures.Percentage, mean and range were used to describe continuous and categorical variables respectively.

\section{Results}

With the mean age of 3.51 years and $S D \pm 5.03$, almost 18 $(60 \%)$ of the cases presented at their infantile period while the earliest coming over to this hospital during the study was onthe 13th day followed by $6(20 \%)$ patients who were $1-5$ years old, $3(10 \%)$ patients of more than 5 to 10 years old and $3(10 \%)$ patients who were aged above 10 years, with the eldest patient as recorded for this study was 13 years old. Among the patients, majority $23(76.7 \%)$ of them have been brought up as male and rest 7 (23.3\%) of them were reared as female (Table-I). Ambiguous genitalia was the main complaint from the patients' side which was seen in $29(96.7 \%)$ patients. Absence of development of secondary sexual characteristics was complained by $1(3.3 \%)$ patient who was 12 years old and one patient (3.3\%) presented with micropenis (Table-II).

Principally, three hormonal assessments were carried outamong the patients- luteinizing hormone (LH), Follicle Stimulating Hormone (FSH), testosterone (T) and 17(OH)P (17 Hydroxy Progesterone). The hormonal assessment showed that $\mathrm{LH}$ was increased by $50 \%$ of the patients, decreased in $16.7 \%$ of the patients and was normal in $33.3 \%$ patients. FSH was increased in $56.6 \%$ of the patients, decreased in $6.7 \%$ of the patients and was normal in $36.7 \%$ patients. The level of testosterone was 
increased in $53.3 \%$ of the patients, decreased in $3.3 \%$ of the patients and was normal in $43.3 \%$ patients. The level of $17(\mathrm{OH})$ $P$ was increased by $50 \%$ of the patients, decreased in $3.3 \%$ of the patients and was normal in $23.3 \%$ patients (Table-III). Patients of the study have been found to be diagnosed with four kinds of disorders among the spectrum of 46 XY DSD. They were partial androgen insensitivity syndrome (PAIS), complete androgen insensitivity syndrome (CAIS), Deficiency of five alpha-reductase (5aRD) and gonadal dysgenesis (GD). It has been recorded that 5 patients had PAIS, 5 patients had CAIS, 3 patients had a deficiency of $5 \mathrm{aRD}$ and 5 patients had $\mathrm{GD}$. Cases remained unclassified under any spectrum at the time of the study were 12 in number.

Among the clinical features of the $46 \mathrm{XY} D S D$, hypospadias was the most common phenotype, found in $17(56.64 \%)$ cases where $5(16.67 \%)$ cases found in patients with PAIS, $3(10 \%)$ cases in patients with CAIS, $2(6.67 \%)$ cases in patients with deficiency of $5 \mathrm{aRD}, 1(3.3 \%)$ case in patients with GD and $6(20 \%)$ cases with hypospadias remained unclassified. Micropeniswasfound in $12(40 \%)$ cases; among them, $1(3.3 \%)$ case was found in PAIS patients, $3(10 \%)$ cases in CAIS patients, $2(6.67 \%)$ cases in $5 \mathrm{aRD}$ deficit patients, $1(3.3 \%)$ case in patients with $\mathrm{GD}$ and 5 $(16.67 \%)$ remained unclassified. The bifid scrotum was identified in $10(33.3 \%)$ cases where $3(10 \%)$ cases were found in PAIS patients, $1(3.3 \%)$ case in CAIS patients, $2(6.67 \%)$ cases in $5 \mathrm{aRD}$ deficit patients and $4(13.3 \%)$ cases of bifid scrotum remained unclassified. Urethral meatus was absent in $1(3.3 \%)$ unclassified case. Absence of left gonad and right gonad were seen in $6(20 \%)$ and $3(10 \%)$ patients respectively wherein both cases $2(6.67 \%)$ cases were in patients with $\mathrm{GD}$ and rests remained unclassified. Patients with gonads palpable in the inguinal region were 2 $(6.67 \%)$, among them one (3.3\%) had PAIS and rest had CAIS. Enlarged clitoris was present in $6(20 \%)$ patients, $3(10 \%)$ cases with $\mathrm{GD}$ and $3(10 \%)$ cases remained unclassified. Vaginal orifice was present in $7(23.3 \%)$ cases where $3(10 \%)$ cases were with CAIS, $1(3.3 \%)$ case was with 5aRD deficiency, 1 (3.3\%) with GD and $2(6.67 \%)$ remained unclassified. Lastly, 1 (3.3\%) patient was identified with the presence of Mullerian structure that was diagnosed with GD (Table-IV). By the time of the study,there were $5(16.6 \%)$ already operated patients, among whom 1 patient had undergone phallus reconstruction, $16(53.3 \%)$ patients were referred to surgeon for subsequent operative treatment, 7 (23.3\%) patients were recommended administration of testosterone and $2(6.7 \%)$ patients were planned to be undergone the required operative procedure.

Table-l: Distribution of patients according to age and sex $(n=30)$

\begin{tabular}{|c|l|c|c|}
\hline Traits & & Frequency & Percentage \\
\hline \multirow{4}{*}{ Age } & 1 year or below & 18 & 60 \\
\cline { 2 - 4 } & $1.1-5$ years & 6 & 20 \\
\cline { 2 - 4 } & $5.1-10$ years & 3 & 10 \\
\cline { 2 - 4 } & More than 10 years & 3 & 10 \\
\hline \multirow{2}{*}{ Sex } & Male & 23 & 76.7 \\
\cline { 2 - 4 } & Female & 7 & 23.3 \\
\hline
\end{tabular}
complaints $(n=30)$

\begin{tabular}{|l|c|c|}
\hline \multicolumn{1}{|c|}{ Features } & Frequency & Percentage \\
\hline Ambiguous Genitalia & 29 & 96.7 \\
\hline Micropenis & 1 & 3.3 \\
\hline $\begin{array}{l}\text { Absence of development of secondary sexual } \\
\text { characteristics }\end{array}$ & 1 & 3.3 \\
\hline
\end{tabular}

Table-III: Hormonal assay of the patients $(n=30)$

\begin{tabular}{|l|r|c|r|}
\hline & Decreased & Normal & Increased \\
\hline LH (Luteinizing Hormone) & $5(16.7 \%)$ & $10(33.3 \%)$ & $15(50 \%)$ \\
\hline FSH (Follicle Stimulating Hormone) & $2(6.7 \%)$ & $11(36.7 \%)$ & $17(56.6 \%)$ \\
\hline T (Testosterone) & $1(3.3 \%)$ & $13(43.3 \%)$ & $16(53.3 \%)$ \\
\hline 17-OHP(17 Hydroxy Progesterone) & $1(3.3 \%)$ & $7(23.3 \%)$ & $15(50 \%)$ \\
\hline
\end{tabular}

Table-IV: Phenotypical expressions* among the etiological diagnosis $(n=30)$

\begin{tabular}{|c|c|c|c|c|c|c|c|}
\hline & \multicolumn{7}{|l|}{ Diagnosis } \\
\hline & & PAIS & CAIS & \begin{tabular}{|c|} 
Deficiency \\
of $5 a R D$ \\
\end{tabular} & GD & $\begin{array}{c}\text { Not } \\
\text { classified }\end{array}$ & Total \\
\hline \multirow{11}{*}{ 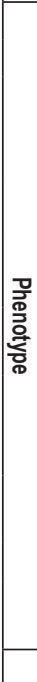 } & Bifid scrotum & $3(10 \%)$ & $1(3.3 \%)$ & $2(6.67 \%)$ & 0 & $4(13.3 \%)$ & $10(33.3 \%)$ \\
\hline & Micro penis & $1(3.3 \%)$ & $3(10 \%)$ & $2(6.67 \%)$ & $1(3.3 \%)$ & $5(16.67 \%)$ & $12(40 \%)$ \\
\hline & $\begin{array}{l}\text { Urethral } \\
\text { meatus } \\
\text { absent }\end{array}$ & 0 & 0 & 0 & 0 & $1(3.3 \%)$ & $1(3.3 \%)$ \\
\hline & Hypospadias & $\begin{array}{r}5 \\
(16.67 \%) \\
\end{array}$ & $3(10 \%)$ & $2(6.67 \%)$ & $1(3.3 \%)$ & $6(20 \%)$ & $17(56.64 \%)$ \\
\hline & \begin{tabular}{|l} 
Left gonad \\
absent
\end{tabular} & 0 & 0 & 0 & $2(6.67 \%)$ & $4(13.3 \%)$ & $6(20 \%)$ \\
\hline & $\begin{array}{l}\text { Right gonad } \\
\text { absent }\end{array}$ & 0 & 0 & 0 & $2(6.67 \%)$ & $1(3.3 \%)$ & $3(10 \%)$ \\
\hline & $\begin{array}{l}\text { One/both } \\
\text { gonads in } \\
\text { inguinalregion }\end{array}$ & $1(3.3 \%)$ & $1(3.3 \%)$ & 0 & 0 & 0 & $2(6.67 \%)$ \\
\hline & $\begin{array}{l}\text { Enlarged } \\
\text { clitoris }\end{array}$ & 0 & 0 & 0 & $3(10 \%)$ & $3(10 \%)$ & $6(20 \%)$ \\
\hline & Vaginal orifice & 0 & $3(10 \%)$ & $1(3.3 \%)$ & $1(3.3 \%)$ & $2(6.67 \%)$ & $7(23.3 \%)$ \\
\hline & $\begin{array}{l}\text { Mullerian } \\
\text { structure }\end{array}$ & 0 & 0 & 0 & $1(3.3 \%)$ & 0 & $1(3.3 \%)$ \\
\hline & Total & $5(16.67 \%)$ & $5(16.67 \%)$ & $3(10 \%)$ & $5(16.67 \%)$ & $12(40 \%)$ & \\
\hline
\end{tabular}

*Multiple presentations

\section{Discussion}

An individual with a chromosomal pattern of one $X$ chromosome and one $Y$ chromosome in each cell, which is the usual chromosomal pattern found in male has ambiguous external genitalia that is not clearly male or female is regarded as $46 \mathrm{XY}$ DSD patient. In some instances, these patients have fully to underdeveloped female reproductive organs while others may present normal external genitalia with discordance in internal structures. They may be raised as male or female according to the gender assigned at birth which often depends on the corresponding resemblance of the genitalia to male or female and later according to the gender identity. Treatment involves corrective surgery and hormone replacement therapy. Patients with 46, XY DSD have discordance between the karyotype and the phenotypical expression regarding external genitalia and gonadal sex. These patients mostly are seen to have an autosomal recessive pattern of inheritance, which 
is correspondent to their $X$ chromosome ${ }^{21,22}$. In comparison to normal $46, X Y$ individuals, patients with $46, X Y$ DSD have lower virilization pattern. Aetiology may be associated with hypoplasia of Leydig cells, enzyme disturbances of testosterone synthesis, a deficit of 5-alfa-reductase enzyme (DEF5a), testicular regression syndrome, gonadal dysgenesis (GD), anorquia, partial or complete androgen insensitivity syndrome (PAIS/CAIS) or ovotesticular DSD ${ }^{23}$. At birth, patients with $46 \mathrm{XY}$ DSD show atypical external genitalia patterns ranging from a male looking phallus to almost normal female genitalia with a slight increase of clitoris. Testes may be located in the abdominal or in inguinal region instead of scrotal folds 5 .

The 30 cases in the present study have been diagnosed with 5 PAIS cases, 5 CAIS cases, $35 \mathrm{aRD}$ deficit cases $5 \mathrm{GD}$ cases. Cases remained unclassified under any spectrum at the time of the study were 12 in number. The most common phenotype of 46 XY DSD was hypospadias which was found among 17 cases mostly in PAIS (16.67\%) and CAIS (10\%) cases, 2 $(6.67 \%)$ cases in patients with deficiency of $5 \mathrm{aRD}, 1$ (3.3\%) case in patients with GD and $6(20 \%)$ cases with hypospadias remained unclassified. Micropenis was found in $12(40 \%)$ cases; among them 1 was with PAIS, 3 were with CAIS, 2 were $5 \mathrm{aRD}, 1$ with $\mathrm{GD}$ and 5 remained unclassified. Bifid scrotum was identified in 10 cases where 3 with PAIS patients, 1 with CAIS patients, 2 with $5 \mathrm{aRD}$ deficit were diagnosed and 4 cases remained unclassified. Urethral meatus was absent in 1 unclassified case. Absence of left or right gonads seen some in GD and rests remained unclassified. Patients with gonads palpable in inguinal region were 2, among them one had PAIS and another had CAIS. Enlarged clitoris was present in 6 patients, 3 cases with GD and 3 cases remained unclassified, Vaginal orifice was present in 7 cases where 3 with CAIS, 1 case was with $5 \mathrm{aRD}$ deficiency, 1 with GD and 2 remained unclassified. Lastly, 1 patient was identified with the presence of Mullerian structure, who was diagnosed with GD. The gender of rearing was male foe 23 patient and female for 7 patients.

Other studies on disorders of sexual development that focused primarily on $46 \mathrm{XY}$ DSD, observed nearly similar results which are substantial with our study findings, described as followed. A prospective study with an assessment of eleven $46 \mathrm{XY}$ DSD patients recorded that 3 cases were diagnosed with 5 alpha-reductase deficiency (5aRD), 2 with partial gonadal dysgenesis, 3 with PAIS, 1 each with ovotesticular, complete gonadal dysgenesis, and CAIS. Gender assigned at birth was female in eight and male in three patients ${ }^{24}$. A retrospective study of medical records of survey data of 93 patients with 46, XY DSD observed that among the patients, $50.5 \%$ had no defined aetiology and $20.4 \%$ had androgen insensitivity syndrome (AIS), They also found that all patients with CAIS had pure gonadal dysgenesis had female genitalia. Others have been diagnosed with genital ambiguity or severe hypospadias and cryptorchidism. The gonads were palpable at the first consultation in $75.3 \%$ of patients ${ }^{5}$. Another study showed, among 102 patients with 46 XY DSD, 32 (31.4\%) had androgen insensitivity syndrome which substantiates with our findings where we found $33.3 \%$ of patients with androgen insensitivity syndrome $e^{25}$. A study with 19 patients with $46 \mathrm{XY}$ DSD found one case with CAIS, $3(15.8 \%)$ cases with PAIS and $4(21.05 \%)$ cases with $5 \mathrm{aRD}^{26}$.

\section{Conclusion}

The most frequent aetiology in the present study was androgen insensitivity syndrome followed by gonadal dysgenesis and the most common phenotype was hypospadias, micropenis and bifid scrotum.A careful clinical evaluation at the neonatal or infantile period can identify most of the DSD cases and precocious diagnosis allows a fora better and earlier therapeutic approach which can avail them to live healthy adulthood.

\section{References}

1. van Mil EG, Hiort $O$. Three out of four: a case discussion on ambiguous genitalia. European Journal of Endocrinology 2008; 159(suppl_1):S91-3.

2. Hughes IA, Houk C, Ahmed SF et al. Consensus statement on management of intersex disorders. Journal of Pediatric Urology 2006; 2(3):148-62.

3. Sandberg DE, Pasterski V, Callens N. Introduction to the Special Section: Disorders of Sex Development. J Pediatr Psychol 2017; 42(5):487-95.

4. Achermann JC, Domenice S, Bachega TASS et al. Disorders of sex development: effect of molecular diagnostics. Nat Rev Endocrinol 2015; 11(8):478-88.

5. Mota BC, Oliveira LMB, Lago Ret al. Clinical profile of 93 cases of $46, X Y$ disorders of sexual development in a referral center. Int Braz J Urol Off J Braz Soc Urol 2015; 41(5):975-81.

6. Sax L: How common is intersex? A response to Anne FaustoSterling. J Sex Res 2002; 39:174-8.

7. Nistal M, Paniagua R, Gonzalez-Peramato $P$ et al. Ovotesticular DSD (true hermaphroditism). Pediatr Dev Pathol 2015; 18:345-52.

8. Skakkebaek NE, Rajpert-De Meyts E, Main KM.Testicular dysgenesis syndrome: An increasingly common developmental disorder with environmental aspects. Hum Reprod 2001; 16:972-8.

9. Nordenvall AS, Frisen L, Nordenstrom Aetal. Population based nationwide study of hypospadias in Sweden, 1973 to 2009: Incidence and risk factors. J Urol 2014; 191:783-9.

10. Nistal M, Paniagua R, Gonzalez-Peramato P et al. Ovotesticular DSD (true hermaphroditism). Pediatr Dev Pathol 2015; 18:345-52.

11. Ostrer H. 46,XY Disorder of sex development and 46,XY complete gonadal dysgenesis. In: Pagon RA, Adam MP, Bird TD, eds. GeneReviews. Seattle, WA: University of Washington, Seattle. http:// www.ncbi.nlm.nih.gov/books/NBK1547/. Published May 21, 2008. Updated September 15, 2009. 
12. Ostrer H. Disorders of sex development (DSDs): An update. J Clin Endocrinol Metab 2014; 99(5):1503-9.

13. Ahmad A, Ayub F, Saleem I et al. Initial assessment of a child with suspected disorder of sex development. JPMA J Pak Med Assoc 2019; 69(5):711-7.

14. Domenice S, Arnhold IJP, Costa EMF et al. 46,XY Disorders of Sexual Development. In: Feingold KR, Anawalt B, Boyce A, Chrousos G, Dungan K, Grossman A, et al., editors. Endotext. South Dartmouth (MA): MDText.com, Inc.; 2000

15. Walia R, Singla M, Vaiphei K et al. Disorders of sex development: a study of 194 cases. Endocr Connect 2018; 7(2):364-71.

16. Praburam Pm. Medical Audit Of Children With Ambiguous Genitalia- Review Of Children Treated Over 18 Years. In 2015.

17. Tan MH, Li J, Xu HE et al. Androgen receptor: structure, role in prostate cancer and drug discovery. Acta Pharmacol Sin 2015; 36:3-23

18. Lee DK, Chang C. Expression and degradation of androgen receptor: mechanism and clinical implication. The Journal of Clinical Endocrinology \& Metabolism 2003; 88(9):4043-54.

19. Atta I, Ibrahim M, Parkash A et al. Etiological diagnosis of under virilized male/ XY disorder of sex development. J coll Physicians Surg Pak 2014; 24:714-8.
20. Cohen-Kettenis PT. Psychosocial and psychosexual aspects of disorders of sex development. Best Practice \& Research Clinical Endocrinology \& Metabolism 2010; 24(2):325-34.

21. Nussbaum RL, Mcinnes RR. Thompson \& Thompson-Genética Médica. Elsevier 2008; 7:111-4.

22. How common is intersex? Intersex Society of North America. Available at https://isna.org/faq/frequency/.

23. Paris F, Gaspari L, Philibert Pet al. Disorders of sex development: Neonatal diagnosis and management. Endocr Dev 2012; 22:56-71.

24. Gangaher A, Chauhan V, Jyotsna VP et al. Gender identity and gender of rearing in $46 \mathrm{XY}$ disorders of sexual development. Indian J Endocrinol Metab 2016; 20(4):536-41.

25. Walia R, Singla M, Vaiphei K et al. Disorders of sex development: A study of 194 cases. Endocr Connect 2018; 7(2):364-71.

26. Vasundhera C, Jyotsna VP, Kandasamy D et al. Clinical, hormonal and radiological profile of $46 \mathrm{XY}$ disorders of sexual development. Indian J Endocrinol Metab 2016; 20(3):300-7. 